\title{
Normative neurophysiologic parameters of the peroneal nerve among adult Sudanese population
}

\begin{abstract}
Background: Nerve conduction studies (NCSs) are an invaluable aid to investigate and quantify the physiological activity of peripheral nerves. They include measurement of sensory and motor conduction velocities and latencies of peripheral nerves which might be influenced by anthropometric factors like age, sex, height, weight, temperature and (body mass index) BMI.

Objective: As mentioned in the companion paper, normative NCS parameters were lacking in Sudan, hence the aim of this study is to establish our own EMG normal neurophysiological values among adult Sudanese people.

Method: A descriptive, analytic, cross sectional study investigating 200 Peroneal nerves of 100 healthy Sudanese people was conducted in Elmagzoub Neuroscience Center; supported by the Faculty of Medicine, National Ribat University, Khartoum, Sudan.

Results: The normative neurophysiologic values of the Left and Right peroneal nerve CMAP (compound muscle action potential) in the whole sample of this work were shown as; latency $(\mathrm{ms})$, amplitude $(\mathrm{mV})$, duration $(\mathrm{ms})$, area $(\mathrm{mVms})$ and conduction velocity $(\mathrm{m} / \mathrm{s})$. The Left Peroneal values were $6.1 \pm 1.7,2.6 \pm 0.5,3.6 \pm 0.9,13.8 \pm 6.1$ and $46.5 \pm 2$, respectively. The right peroneal values were $5.7 \pm 2.3,3.6 \pm 0.9,5.7 \pm 1.3,15.7 \pm 7$ and $48.3 \pm 4.5$, respectively.

Conclusion: Most EMG laboratories worldwide depend on reference values originated in Caucasian populations. Consequently, this is a second of serial NCSs of common peripheral nerves, performed in Afro-Arab ethnic Sudanese population, aiming to determine if there are any diverse values between this group and the aforementioned. Eventually this work will allow us to have our own NCS reference parameters.
\end{abstract}

Special Issue - 2020

\author{
Hussam Mohammed A Hameed, 1,3 \\ Mohammed Salah Elmagzoub, ${ }^{2,3}$ Ahmed \\ Hassan Ahmed Hassan ${ }^{4}$ \\ 'Department of Respiratory Care, College of Applied Medical \\ Sciences - Jubail, Imam Abdulrahman Bin Faisal University, Saudi \\ Arabia \\ ${ }^{2}$ Department of Neuroscience Technology, College of Applied \\ Medical Sciences - Jubail, Imam Abdulrahman Bin Faisal \\ University, Saudi Arabia \\ ${ }^{3}$ Faculty of Medicine, National Ribat University, Khartoum, Sudan \\ ${ }^{4}$ Faculty of Nursing, Jazan University, Jazan, Saudi Arabia
}

\begin{abstract}
Correspondence: Mohammed Salah Elmagzoub; Department of Neuroscience Technology, College of Applied Medical Sciences - Jubail, Imam Abdulrahman Bin Faisal University, Saudi Arabia,Email msmagoub@yahoo.com,msmali@iau.edu.sa
\end{abstract}

Received: June 25, 2020 | Published: July 30, 2020

\section{Introduction}

Nerve conduction study (NCS) is a test commonly used to evaluate the function, especially the ability of electrical conduction, of the motor and sensory nerves of the human body. ${ }^{1,2}$ NCS are useful in evaluating diseases of the peripheral nervous system. Testing help to localize the site or level of the lesion; determining if the pathology involves the peripheral nerve, neuromuscular junction, plexus, nerve root or anterior horn cells. Because of the steady improvement and standardization of methods, NCSs have become a reliable investigation in clinical settings. They are now widely used not only for precise localization of a lesion, but also for identifying the pathophysiology by distinguishing axonal loss from demyelination. ${ }^{3-5}$ Conduction velocity has been also used in genetic and epidemiologic studies for detecting hereditary peripheral nerve disorder prior to development of clinical signs. ${ }^{6,7}$ They are also used to monitor nerve function over time to determine disease progression, assess the complications of treatment (like chemotherapy), as well as categorizing the disease course if acute, sub-acute or chronic. ${ }^{8-11}$

The reference values for NCSs vary considerably from population to population and from region to region. The majority of nerve conduction studies are based on Caucasian subjects, therefore this study is designed to determine the effect of specific personal factors as age, gender, height and temperature and body mass index on nerve conduction velocity among Sudanese subjects and eventually to have our own NCS parameters.
Most EMG laboratories worldwide depend on reference values originated on Caucasian populations. ${ }^{12,13}$ Consequently, this is a second of serial NCSs of common peripheral nerves, conducted in an Afro-Arab ethnic Sudanese population, aiming to determine if there are any diverse values between this group and the aforementioned. Eventually this work will allow us to have our own NCS reference parameters.

Anatomically, the peroneal nerve is formed by axons from L4, L5, $\mathrm{S} 1$ and $\mathrm{S} 2$ roots. As the common fibular nerve exits the popliteal fossa, it courses around the lateral aspect of the leg just below the head of the fibula. Here it is apposed with fibula and gives off two branches, the superficial peroneal branch and deep peroneal branch. ${ }^{15-19}$ The deep peroneal nerve innervates the muscles of the anterior compartment of the leg while the superficial peroneal nerve supplies the muscles of the lateral compartment of the leg. ${ }^{20-23}$

\section{Methods}

\section{Subject selection and sample size}

Two hundred Peroneal nerves of 100 healthy Sudanese adults, (64 males and 36 females) of a range of age 18 to 60 years and a mean of (35.9 \pm 7.5$)$, were included in this descriptive, analytic, cross sectional study. The study was conducted in Elmagzoub Neuroscience Centre, supported by the Faculty of Medicine, National Ribat University. All individuals were screened for inclusion criteria that comprised normal neurological physical examination with no symptoms and signs of 
neuropathy. No underlying possible cause of peripheral neuropathy. All those with chronic illness as diabetes and hypertension and patients who are asymptomatic with previous bone fractures or nerve injuries were excluded from the study.

\section{Equipment and procedure}

As in the companion paper, an 8 channels EMG machine (Viaysis-select) was used for the performance of NCSs. Machine settings: Sensitivity, $5 \mathrm{mV} /$ division; Low frequency filter, $2-3 \mathrm{~Hz}$; High frequency filter, $10 \mathrm{kHz}$; Sweep speed, $5 \mathrm{msec} /$ division. Data was saved in a standard Microsoft Excel database. All testing was conducted in air-conditioned rooms with the temperature maintained in the range between $20-26^{\circ} \mathrm{C}$. Body temperature was recorded from the axilla by a digital thermometer. Skin temperature recorded ranged from 35 to $37.7^{\circ} \mathrm{C}$. Data were collected for the following parameters: distal latency measured from the onset of action potential, amplitude of compound muscle action potential (CMAP), duration, area and conduction velocity.

\section{Stimulation and recording procedures}

The peroneal nerve was stimulated with a bipolar surface stimulating electrode (S403) at three sites along its course, at ankle, fibular head and popliteal fossa. At ankle anteriorly and slightly lateral to the tibialis anterior tendon. Below fibula one to two fingerbreadths inferior to fibular head. At knee the peroneal nerve was stimulated over the palpable portion of the peroneal nerve adjacent to the external hamstring tendons in the lateral popliteal fossa $5-6 \mathrm{~cm}$ proximal to the fibula head.

The active recording electrode was placed over the extensor digitorum brevis muscle approximately $1 \mathrm{~cm}$ distal to the bony prominence of the talus over the metatarsophalangeal joint. The reference electrode was placed over the lateral surface of the fifth digit. The ground electrode was placed over the dorsum of the ankle.

\section{F-wave stimulation}

The cathode is positioned over the anterior ankle, as for distal peroneal recording. Data were analyzed using Statistical Package for Social Sciences (SPSS) software version 16 and presented as mean and standard deviation and range. Correlation coefficient was used to assess the relation between the age, weight, height, BMI and temperature and the conduction velocity of the peroneal nerve. $\mathrm{P}$ value is considered significant if $<0.05$.

\section{Results}

This is a descriptive, analytic, cross sectional study involving 200 peroneal nerves of 100 healthy Sudanese individuals (64 males and 36 females) of 18 to 60 years old with an overall average of (35.9 \pm 7.2). This indicates a moderate age homogeneous population. Ninety seven percent of them were right-handed. They showed an overall average weight, height, BMI and temperature of $71.5 \mathrm{Kg}, 172.3 \mathrm{~cm}, 24.1$ and $36.2^{\circ} \mathrm{C}$ respectively.

The normative neurophysiologic values of the Left and Right peroneal nerve CMAP (compound muscle action potential) in the whole sample of this work were shown as; latency (ms), amplitude $(\mathrm{mV})$, duration $(\mathrm{ms})$, area $(\mathrm{mVms})$ and conduction velocity $(\mathrm{m} / \mathrm{s})$. The left peroneal values were $6.1 \pm 1.7,2.6 \pm 0.5,3.6 \pm 0.9,13.8 \pm 6.1$ and $46.5 \pm 2$ respectively (Table 1 ). The right peroneal values were $5.7 \pm 2.3$, $3.6 \pm 0.9,5.7 \pm 1.3,15.7 \pm 7$ and $48.3 \pm 4.5$ respectively (Table 2 ).

Further segregation of these results in the whole sample according to gender and left versus right peroneal nerves; showed that the CMAP latency $(\mathrm{ms})$, amplitude $(\mathrm{mV})$, duration $(\mathrm{ms})$, area $(\mathrm{mVms})$ and conduction velocity $(\mathrm{m} / \mathrm{s})$ of left peroneal nerve in males were $6.4 \pm 1.9,2.7 \pm 0.5,3.8 \pm 0.9,13.8 \pm 6.1$ and $46.4 \pm 2.1$ respectively (Table $3)$. The right peroneal parameters were $5.9 \pm 2.4,3.8 \pm 0.9,5.7 \pm 1.3$, $16.6 \pm 7.5$ and $47.2 \pm 3.6$ respectively (Table 4 ).

Table I Motor conduction values of the Left peroneal nerve for the whole study sample (I00 nerves)

\begin{tabular}{|c|c|c|c|c|}
\hline Stimulation site & Descriptive statistics & Minimum & Maximum & Mean \pm SD \\
\hline \multirow{4}{*}{ At the ankle } & Latency (ms) & 1.9 & 4.1 & $2.6 \pm 0.5$ \\
\hline & Duration (ms) & 2 & 5.9 & $3.6 \pm 0.9$ \\
\hline & Amplitude (mV) & 3.8 & 16.8 & $6.1 \pm 1.7$ \\
\hline & Area $(\mathrm{mVms})$ & 0.8 & 35.2 & $|3.8 \pm 6|$. \\
\hline \multirow{5}{*}{ At the fibular head } & Latency (ms) & 0.6 & 36 & $5.1 \pm 3.7$ \\
\hline & Duration (ms) & 2.8 & 21.1 & $\mid I .1 \pm 2$ \\
\hline & Amplitude (mV) & 3.4 & 19.5 & $6.6 \pm 2$ \\
\hline & Area $(\mathrm{mVms})$ & 0.8 & 35.1 & $13.8 \pm 6.1$ \\
\hline & Conduction velocity $(\mathrm{m} / \mathrm{s})$ Ankle -fibular head & & & $46.5 \pm 2$ \\
\hline \multirow{5}{*}{ At the popliteal fossa } & Latency (ms) & 0.5 & 10.1 & $4.3 \pm 1.9$ \\
\hline & Duration (ms) & 9.3 & 43 & $13.3 \pm 3.4$ \\
\hline & Amplitude (mV) & 3.8 & 22.3 & $6.3 \pm 2$ \\
\hline & Area $(\mathrm{mVms})$ & 1.4 & 36.5 & $13.4 \pm 6.4$ \\
\hline & Conduction velocity $(\mathrm{m} / \mathrm{s})$ Fibular head-popliteal fossa & 36 & 60 & $48.1 \pm 4$ \\
\hline Fwave (ms) & & 34 & 62 & $45.7 \pm 3.4$ \\
\hline
\end{tabular}


Table 2 Motor conduction findings of the right peroneal nerve in the whole study sample ( 100 nerves)

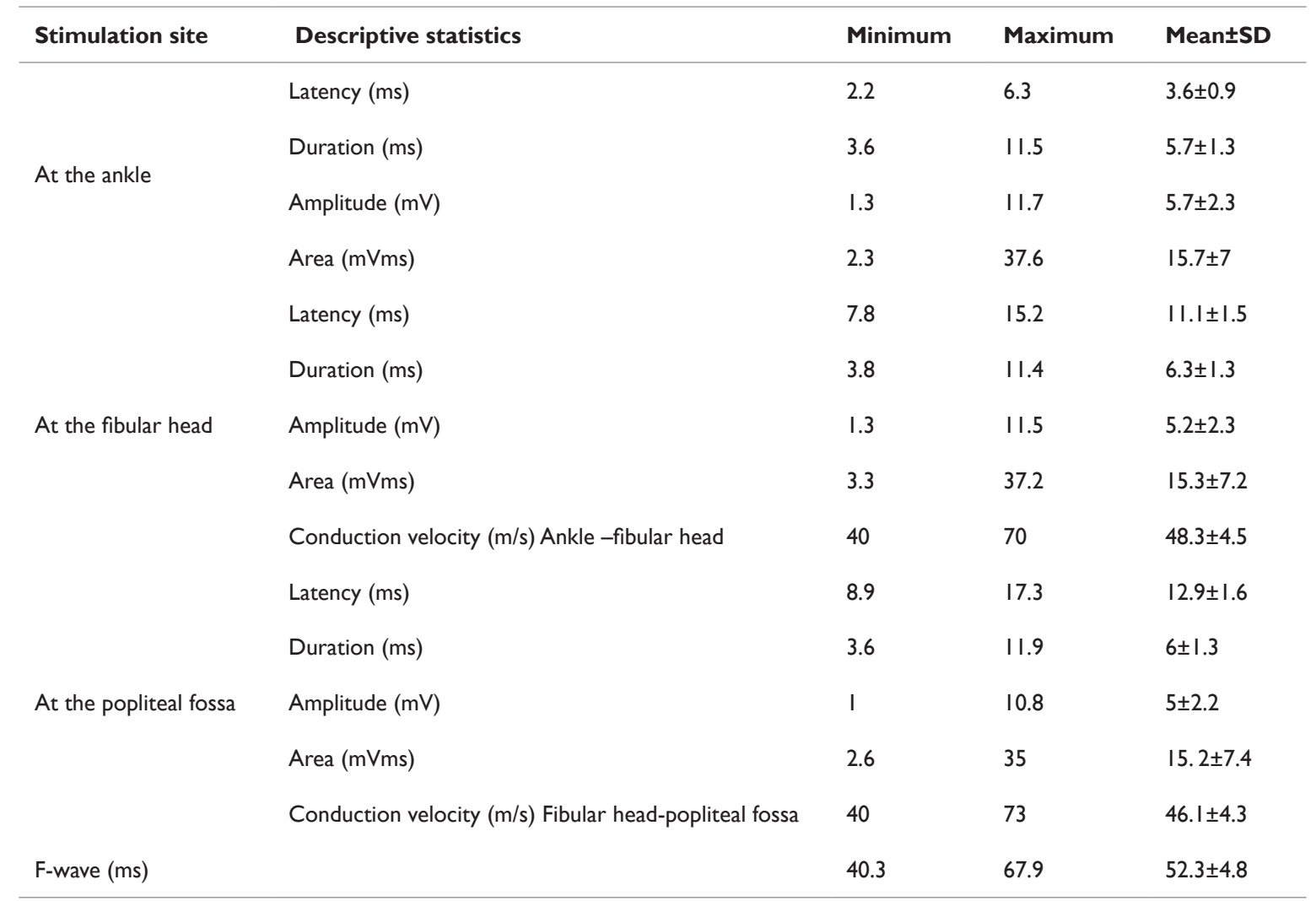

Table 3 Motor conduction parameters of the left peroneal nerve in males (64 nerves)

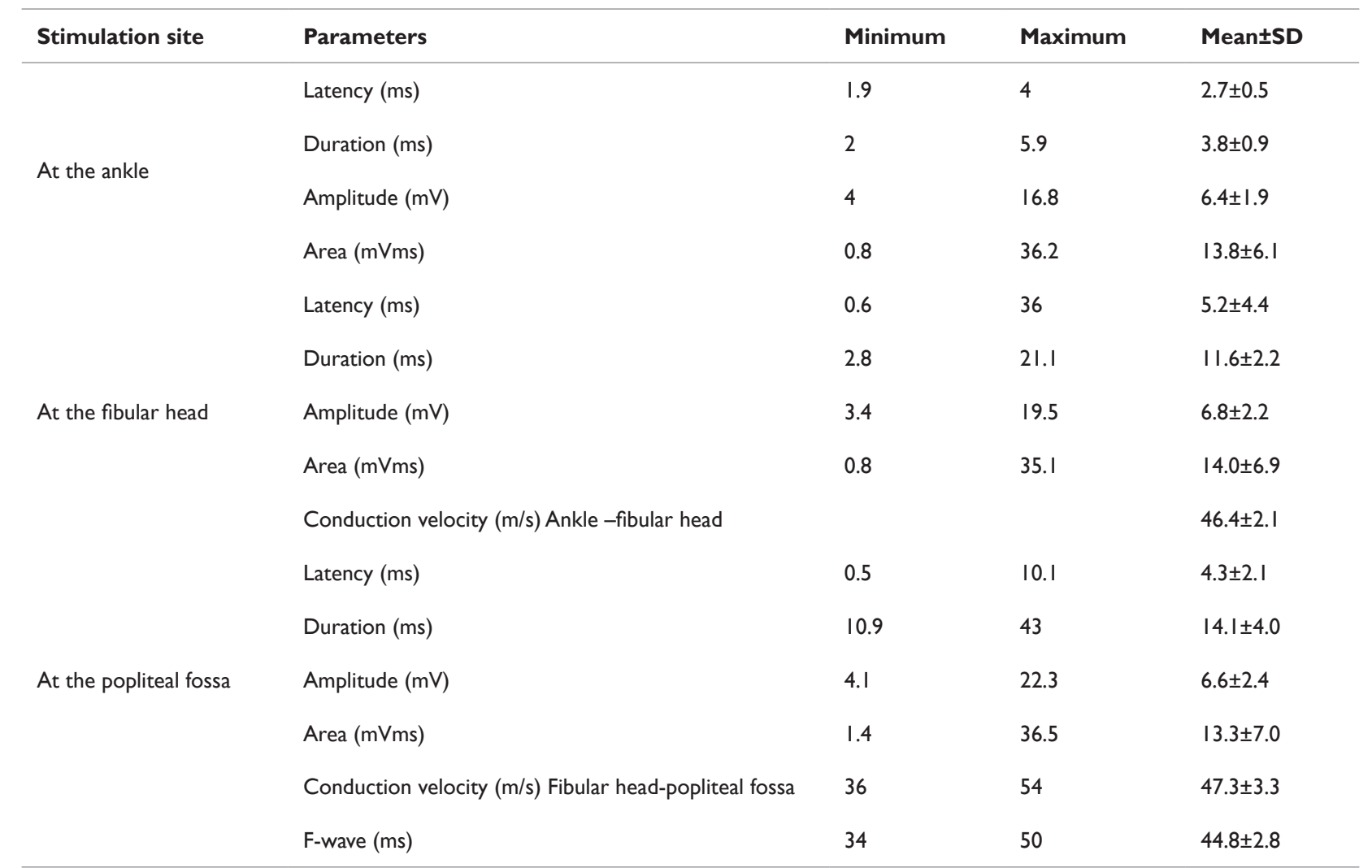


Table 4 Motor conduction parameters of the right peroneal nerve in males (64 nerves)

\begin{tabular}{|c|c|c|c|c|}
\hline Stimulation site & Parameters & Minimum & Maximum & Mean $\pm S D$ \\
\hline \multirow{4}{*}{ At the ankle } & Latency (ms) & 2.2 & 6.3 & $3.8 \pm 0.9$ \\
\hline & Duration (ms) & 3.6 & 11.5 & $5.753 \pm 1.3$ \\
\hline & Amplitude (mV) & 1.3 & 11.7 & $5.895 \pm 2.4$ \\
\hline & Area $(\mathrm{mVms})$ & 2.3 & 37.6 & $16.552 \pm 7.5$ \\
\hline \multirow{5}{*}{ At the fibular head } & Latency (ms) & 8.8 & 15.2 & I I. $627 \pm 1.4$ \\
\hline & Duration (ms) & 4 & 10.8 & $6.27 \pm 1.2$ \\
\hline & Amplitude (mV) & 1.3 & 11.5 & $5.434 \pm 2.5$ \\
\hline & Area $(\mathrm{mVms})$ & 3.3 & 37.2 & $16.109 \pm 7.7$ \\
\hline & Conduction velocity $(\mathrm{m} / \mathrm{s})$ Ankle -fibular head & 40 & 61 & $47.23 \pm 3.6$ \\
\hline \multirow{5}{*}{ At the popliteal fossa } & Latency (ms) & 10.6 & 17.3 & $\mid 3.534 \pm 1.4$ \\
\hline & Duration (ms) & 3.6 & 11.9 & $6.164 \pm 1.2$ \\
\hline & Amplitude (mV) & I & 10.8 & $5.234 \pm 2.4$ \\
\hline & Area $(\mathrm{mVms})$ & 2.6 & 35 & $16.091 \pm 7.9$ \\
\hline & Conduction velocity $(\mathrm{m} / \mathrm{s})$ Fibular head-popliteal fossa & 40 & 57 & $45.28 \pm 3.1$ \\
\hline F-wave (ms) & & 40.3 & 67.9 & $52.94 \pm 4.7$ \\
\hline
\end{tabular}

On the other hand, the normative CMAP latency (ms), amplitude $(\mathrm{mV})$, duration $(\mathrm{ms})$, area $(\mathrm{mVms})$ and conduction velocity $(\mathrm{m} / \mathrm{s})$ of the left peroneal nerve in females were; $6.2 \pm 0.5,3 \pm 0.8,4.1 \pm 0.6$, $14.1 \pm 6.1$ and $48.3 \pm 1$ respectively (Table 5 ); while the right peroneal values were $5.2 \pm 2,3.4 \pm 0.7,5.5 \pm 1.1,14.1 \pm 5.8$ and $50.1 \pm 5.5$ (Table 6). Table 7 shows a comparison between the results of the present study and those reported by other investigators worldwide.

Table 5 Motor conduction parameters of the left peroneal nerve in female ( 36 nerves)

\begin{tabular}{|c|c|c|c|c|}
\hline Stimulation site & Parameters & Minimum & Maximum & Mean \pm SD \\
\hline \multirow{4}{*}{ At the ankle } & Latency (ms) & 2.2 & 2.8 & $2.5 \pm 0.3$ \\
\hline & Duration (ms) & 2.1 & 3.6 & $3.0 \pm 0.6$ \\
\hline & Amplitude (mV) & 4.3 & 6.8 & $5.6 \pm 1.0$ \\
\hline & Area (mVms) & 6.4 & 29.9 & $\mid 4.1 \pm 6.0$ \\
\hline \multirow{5}{*}{ At the fibular head } & Latency (ms) & 3.9 & 5.6 & $5.1 \pm 0.7$ \\
\hline & Duration (ms) & 8 & 11 & $9.8 \pm 0.9$ \\
\hline & Amplitude (mV) & 5 & 8.5 & $6.1 \pm 1.3$ \\
\hline & Area $(\mathrm{mVms})$ & 9.8 & 18 & $14 \pm 2.5$ \\
\hline & Conduction velocity $(\mathrm{m} / \mathrm{s})$ Ankle -fibular head & 47 & 58 & $5 I \pm 4.2$ \\
\hline \multirow{5}{*}{ At the popliteal fossa } & Latency (ms) & 3.4 & 5.9 & $4.6 \pm 0.8$ \\
\hline & Duration (ms) & 10 & 12.2 & $11.5 \pm 0.7$ \\
\hline & Amplitude (mV) & 4.7 & 8.3 & $5.7 \pm 1.3$ \\
\hline & Area $(\mathrm{mVms})$ & 9.3 & 20.4 & $14.0 \pm 4.1$ \\
\hline & Conduction velocity (M/s) Fibular head-popliteal fossa & 43 & 59 & $49.7 \pm 4.4$ \\
\hline F-wave (ms) & & 42 & 47 & $45.9 \pm 1.8$ \\
\hline
\end{tabular}


Table 6 Motor conduction parameters of the right peroneal nerve in female (36 nerves)

\begin{tabular}{|c|c|c|c|c|}
\hline Stimulation site & Parameters & Minimum & Maximum & Mean \pm SD \\
\hline \multirow{4}{*}{ At the ankle } & Latency (ms) & 2.2 & 5.2 & $3.35 \pm 0.7$ \\
\hline & Duration (ms) & 3.9 & 8.1 & $5.5 \pm 1.1$ \\
\hline & Amplitude (mV) & 2.3 & 9.8 & $5.2 \pm 2.0$ \\
\hline & Area $(\mathrm{mVms})$ & 6.4 & 29.9 & $|4| \pm 5.8$. \\
\hline \multirow{5}{*}{ At the fibular head } & Latency (ms) & 7.8 & 13.9 & $10.1 \pm 1.3$ \\
\hline & Duration (ms) & 3.8 & 11.4 & $6.3 \pm 1.5$ \\
\hline & Amplitude (mV) & 2 & 9.6 & $4.8 \pm 2.0$ \\
\hline & Area $(\mathrm{mVms})$ & 5.8 & 28.1 & $13.7 \pm 5.9$ \\
\hline & Conduction velocity $(\mathrm{m} / \mathrm{s})$ Ankle -fibular head & 40 & 70 & $50.1 \pm 5.5$ \\
\hline \multirow{5}{*}{ At the popliteal fossa } & Latency (ms) & 8.9 & 16.1 & $11.9 \pm 1.5$ \\
\hline & Duration (ms) & 3.7 & 10.8 & $5.7 \pm 1.5$ \\
\hline & Amplitude (mV) & 1.9 & 9.4 & $4.7 \pm 1.9$ \\
\hline & Area $(\mathrm{mVms})$ & 4.9 & 28.3 & $13.5 \pm 6 . \mid$ \\
\hline & Conduction velocity (m/s) Fibular head-popliteal fossa & 41 & 73 & $47.6 \pm 5.6$ \\
\hline F-wave (ms) & & 42.1 & 59.6 & $51.3 \pm 4.9$ \\
\hline
\end{tabular}

Table $7 \mathrm{~A}$ comparison of nerve conduction parameters of the peroneal nerve in the present study and some of those reported in the literature

\begin{tabular}{|c|c|c|c|c|c|c|}
\hline & $\begin{array}{l}\text { Onset latency } \\
\text { (ms) }\end{array}$ & Amplitude (mV) & $\begin{array}{l}\text { Conduction } \\
\text { velocity }(\mathrm{M} / \mathrm{s})\end{array}$ & F-wave (ms) & Area $(\mathrm{mVms})$ & $\begin{array}{l}\text { Duration } \\
\text { (ms) }\end{array}$ \\
\hline Present study $(n=200)$ & $3.6 \pm 0.9$ & $5.7 \pm 2.3$ & $48.3 \pm 4.5$ & $52.3 \pm 4.8$ & $15.7 \pm 7$ & $5.7 \pm 1.3$ \\
\hline Buschbacher $^{29}(n=242)$ & $4.8 \pm 0.8$ & $\begin{array}{l}6.8 \pm 2.5 \text { (young) } \\
5.1 \pm 2.5 \text { (old) }\end{array}$ & $46.5 \pm 4.5$ & $50.2 \pm 5.5$ & & \\
\hline Thakur et $\mathrm{a}^{24}(\mathrm{n}=34)$ & $5.88 \pm 0.93$ & $4.64 \pm 2.15$ & & $42 \pm 3.2$ & & \\
\hline $\operatorname{Farqad}^{25}(n=5342)$ & $3.73 \pm 0.63$ & $8.22 \pm 3.61$ & $49.96 \pm 4.76$ & $48.59 \pm 4.26$ & & \\
\hline $\operatorname{Kimura}^{28}(n=60)$ & $3.77 \pm 0.86$ & $5.1 \pm 2.3$ & $48.3 \pm 3.9$ & $48.4 \pm 4.0$ & & \\
\hline Karagoz et al. ${ }^{31}(n=17)$ & & $7.6 \pm 1.6$ & $57.4 \pm 3.6$ & & & \\
\hline
\end{tabular}

\section{Discussion}

Nerve Conduction Studies values vary considerably from one population to the other and eventually regionally. Most EMG laboratories worldwide depend on reference values originated on Caucasian populations. Consequently, this is a second of serial NCSs of common peripheral nerves, conducted in an Afro-Arab ethnic Sudanese population, aiming to determine if there are any diverse values between this group and the aforementioned. Furthermore, to study the effect of age, gender, height, temperature and body mass index on nerve conduction velocity among Sudanese subjects, and eventually have our own NCS parameters reference.

The Peroneal nerve conduction parameters obtained in this work agree with the previous studies of Thakur ${ }^{24}$ Farqad et al. ${ }^{25}$ Palve et al ${ }^{26}$ and Verdú et al. ${ }^{27}$ and to a lesser extent with other studies worldwide. $^{28-32}(25,26,29,32)$. The onset latency and conduction velocity correlated favorably with their work, the only difference was in amplitude which could be attributed to a variety of causes. Firstly, the age of the subjects studied; most studies investigated middle aged subjects, including this study, whereas the study reported by Farqad et al was extended to include younger groups (below 18 years) and older groups (above 80 years). Secondly, the diversity of methods and techniques used in NCS; in the study reported by Farqad et al., they measured the amplitude from peak to peak, while in our study the amplitude was measured from baseline to peak which could explain the higher amplitude in their study. Thirdly, the type of electrode used could also be a source of variation. Surface electrodes used in our study and Buschbacher are designed to give information about the whole muscle stimulated. While Farqad's study used needle electrode that record from only a small area of muscle or nerve, which provide more complex information and making numerical analysis difficult. Finally, ethnic considerations; as most studies were done on Caucasians, others on Asians. However, none of the studies established a reference for Blacks or Afro-Arab. Nevertheless, it is difficult to attribute the difference to a single factor.

The peroneal nerve F-wave bilaterally in this study nearly match that reported by Buschbacher, however it was more prolonged than that reported by Thakur, ${ }^{24}$ Farqad ${ }^{25}$ and Kimura. ${ }^{28}$

Interestingly, when comparing the conduction parameter of the left and right peroneal nerve, showed higher amplitude and faster 
conduction velocity values in the left than in the right nerve. This corresponds to the findings of Mossa et al., the slow value of nerve conduction velocity of motor fiber of peroneal nerve of the right dominant leg in men and women as compared to the left leg may be explained by a delay in conduction velocity as physical activity and repetitive motion may cause stretching of nerve with unyielding musculotendinous compartments followed by fascicular thickening. ${ }^{1}$

Gender differences of the motor conduction of the peroneal nerve was found highly significant with males having low values compared to females. These coincide with the findings of Mahinda Kommalage and Sampath Gunawardena in their work in the ulnar nerve. Robinson et al. showed that influence of gender is due to height and not the gender per se. Additional factor that may be attributed to gender difference is the anatomical variation between males and female. Rivner et al. showed that these deviations with age and height, did not show this relationship with gender. ${ }^{13}$

There was a negative weak correlation between age and conduction velocity of the peroneal nerve in this study. However, some studies showed a strong negative correlation between age and conduction velocity. ${ }^{13,24,25,27}$ In agreement with our study, Buschbacher in his testing the peroneal nerve motor conduction to the extensor digitorum brevis found a decrease in CMAP amplitude in older age group as compared to younger individuals. This low amplitude could be explained by the fact that, normal aging process induces loss of terminal motor nerve fibers, a decrease in skeletal muscle mass and ultimately a decrease in motor unit size. Hence, age adjustment is necessary for the specificity and sensitivity of establishing normal NCS reference data.

This study showed also an existence of a negative correlation between conduction velocity and body weight, height and BMI.

\section{Acknowledgments}

None.

\section{Conflicts of interest}

The authors declare no conflicts of interest.

\section{References}

1. Mossa M Marbut, Raja S Najim, Muammar Abdul Mohsen. Determination of normal values of nerve conduction of Tibial and Peroneal nerves among normal healthy subjects. Tikrit Medical Journal. 2012;18(2):1-8

2. Ralph M Buschbacher, Nathan D Phrahlow. Manual of nerve conduction studies. 2nd edn. Demos Medical Publishing, LLC, 2006;167-169.

3. Michael J Aminoff. Aminoff's Electrodiagnosis in Clinical Neurology. 6th edn, Elsevier Inc; nerve conduction study. 2012:289-301.

4. Mohamed Saufi Awang, Jafri Malin Abdullah, Mohd Rusli Abdullah, et al. Nerve Conduction Study Among Healthy Malays. The influence of age, height and body mass index on median, ulnar, common peroneal and sural nerves. J Med Sci. 2006;13(2):19-23.

5. Asa J Wilbourn. Sensory nerve conduction studies. J Clin Neurophysiol. 1994;11(6):587.

6. James W Albers. Nerve conduction manual. 1995:2-10.

7. Sunil chouhan. Motor nerve conduction studies of Median nerve in young adult group. Int J Biol Med Res. 2012;3(2):1751-1753.

8. Jun IGmura. Principles and pitfalls of nerve conduction studies. Ann Neurol. ;16:415-429.

9. William Huynh Matthew C Kiernan. Nerve conduction studies Australian Family Physician. 2011;40(9):693-697.
10. Roger A Brumback, Gary M Baune, David W Roberts, et al. Pictorial Report Form for Nerve Conduction Studies. 1981;61(10):1457-1458.

11. Dianna Quan, Shwan J Bird. Nerve Conduction Studies and Electromyography in the Evaluation of Peripheral Nerve Injuries. The University of Pennsylvania Orthopaedic Journal. 1999;12:45-51.

12. J McKnight, PG Nicholls, Das Loretta, et al. Reference values for nerve function assessments among a study population in northern India. Neurology Asia. 2010;15(1):39-54.

13. Mahinda Kommalage, Sampath Gunawardena. Influence of Age, Gender, and Sidedness on Ulnar Nerve Conduction. J Clin Neurophysiol. 2013;30(1):67-72.

14. England JD, Gronseth GS, Franklin G, et al. Distal symmetrical polyneuropathy 2005;31(1):113-123.

15. Chummy S Sinnatamby. Last's anatomy regional and applied; Churchill . 10th edn. 1999:127-128.

16. Henry Gray. Gray's Anatomy; 40th edn, Churchill Livingstone 2008;964 -965 .

17. Stewart JD. Foot drop: where, why and what to do? Pract Neurol. 2008;8(3):158-169.

18. Richard S Snell. Clinical Anatomy by Regions. 9th edn. Lippincott Williams and Wilkins. 2011;476-482.

19. David C Preston, Barbara E Shapiro. Electromyography and Neuromuscular Disorders. Clinical-Electrophysiologic Correlations. 3rd edn, Elsevier 2013; 19- 61.

20. Somayaji Nagabhooshana, Venkata Ramana Vollala, et al. Anomalous superficial peroneal nerve and variant cutaneous innervation of the sural nerve on the dorsum of the foot. a case report.; Cases Journal. 2009;2:197.

21. Blair JM, Botte MJ. Surgical anatomy of the superficial peroneal nerve in the ankle and foot. Clinical Orthopedics. 1994;305:229-238.

22. Pacha D Carrera A, Llusa M, et al. Clinical anatomy of the superficial peroneal nerve in the distal leg. Eur J Anat. 2003;:15-20 .

23. Bergman RA, Thompson SA, Afifi AK. Compendium of Human Anatomic Variations. Munich: Urban and Schwarzenberg; 1988:146-147.

24. Thakur D, Paudel BH, Jha CB. Nerve Conduction study in healthy individuals a preliminary age based study. Kathmandu University Medical Journal. 2010;8(3):311-316.

25. Farqad B Hamdan. Nerve conduction study in healthy Iraqis: normative data. Iraqi journal of medical sciences. 2009;7(2):75-92.

26. Palve Suchitra, Palve Sachin. Impact of aging on nerve conduction velocities and late responses in healthy individuals. Journal of Neurosciences in Rural Practice. 2018; 9(1):112-116.

27. Verdú E, Ceballos D, Vilches JJ, et al. Influence of aging on peripheral nerve function and regeneration. J Peripher Nerv Syst. 2000;5:191-208.

28. Kimura J. Electrodiagnosis in diseases of nerve and muscle: principles and practice. 3rd edn, Philadelphia, Davis: Oxford medicine. 2001:131-168.

29. Buschbacher RM. Reference values for peroneal nerve motor conduction to the tibialis anterior and for peroneal vs. tibial latencies. Am J Phys Med Rehabil. 2003;82(4):296-301.

30. Browne JA, Morris M. Variant superficial fibular (peroneal) nerve anatomy in the middle third of the lateral leg. Clin Anat. 2007; 20(8):996-997.

31. Karagoz E, Tanridag T, Karlikaya G, et al. The electrophysiology of diabetic neuropathy. Internet J Neurol. 2005;5(1):1-8

32. Sandra MBarrera-Castro, Fernando Ortiz-Corredor. Young adults' lower limb neuroconduction study reference values. Public health magazine. 2014;16(3):443-452. 